\title{
Recommended musculoskeletal and sports ultrasound terminology: a Delphi-based consensus statement
}

\author{
Mederic M Hall (D) ,' Georgina M Allen, ${ }^{2}$ Sandra Allison (D) ${ }^{3}$ Joseph Craig, ${ }^{4}$ \\ Joseph P DeAngelis, ${ }^{5}$ Patricia B Delzell, ${ }^{6}$ Jonathan T Finnoff, ${ }^{7,8}$ Rachel M Frank, ${ }^{9}$ \\ Atul Gupta, ${ }^{10}$ Douglas Hoffman, ${ }^{11}$ Jon A Jacobson, ${ }^{12}$ Samer Narouze, ${ }^{13}$ \\ Levon Nazarian, ${ }^{14}$ Kentaro Onishi, ${ }^{15}$ Jeremiah Wayne Ray, ${ }^{16}$ Luca Maria Sconfienza, ${ }^{17,18}$ \\ Jay Smith, ${ }^{8,19}$ Alberto Tagliafico ${ }^{20,21}$
}

The following societies have endorsed this statement: American Institute of Ultrasound in Medicine, American Medical Society for Sports Medicine, American Orthopaedic Society for Sports Medicine, American Society of Regional Anesthesia and Pain Medicine, Canadian Academy of Sport and Exercise Medicine, European Society of Musculoskeletal Radiology, Society of Interventional Radiology and Society of Skeletal Radiology. The American Academy of Physical Medicine and Rehabilitation has affirmed the value of the statement.

For numbered affiliations see end of article.

\section{Correspondence to}

Dr Mederic M Hall, Orthopedics and Rehabilitation, The University of lowa Roy J and Lucille A Carver College of Medicine, lowa City, IA 52242, USA; mederic-hall@uiowa.edu

(C) 2022 BMJ Publishing Group Limited. All rights reserved. This article is being published concurrently in Journal of Ultrasound in Medicine and British Journal of Sports Medicine. The article is identical except for minor stylistic and spelling differences in keeping with each journal's style. Citations from either of the two journals can be used when citing this article.

Accepted 27 December 2021

Check for updates

(c) Author(s) (or their employer(s)) 2022. No commercial re-use. See rights and permissions. Published by BMJ.

\footnotetext{
To cite: Hall MM,

Allen GM, Allison S, et al. Br J Sports Med Epub ahead of print: [please include Day Month Year]. doi:10.1136/ bjsports-2021-105114
}

\section{ABSTRACT}

The current lack of agreement regarding standardised terminology in musculoskeletal and sports ultrasound presents challenges in education, clinical practice and research. This consensus was developed to provide a reference to improve clarity and consistency in communication. A multidisciplinary expert panel was convened consisting of 18 members representing multiple specialty societies identified as key stakeholders in musculoskeletal and sports ultrasound. A Delphi process was used to reach consensus, which was defined as group level agreement of $>80 \%$. Content was organised into seven general topics including: (1) general definitions, (2) equipment and transducer manipulation, (3) anatomical and descriptive terminology, (4) pathology, (5) procedural terminology, (6) image labelling and (7) documentation. Terms and definitions which reached consensus agreement are presented herein. The historic use of multiple similar terms in the absence of precise definitions has led to confusion when conveying information between colleagues, patients and third-party payers. This multidisciplinary expert consensus addresses multiple areas of variability in diagnostic ultrasound imaging and ultrasound-guided procedures related to musculoskeletal and sports medicine.

\section{INTRODUCTION}

The use of ultrasound for diagnostic imaging and procedural guidance in musculoskeletal and sports
Box 1 Musculoskeletal and sports ultrasound terms and definitions outline

1. General.

2. Equipment and tansducer manipulation.

3. Anatomical and descriptive.

4. Pathology.

5. Procedural.

6. Image labelling.

7. Documentation.

medicine has increased dramatically and involves multiple disciplines and subspecialties. A lack of consensus regarding standardised terminology can lead to confusion when conveying information between colleagues for clinical and research purposes. Our learners often struggle as different terms are used to describe simple actions such as transducer movement and imaging planes. Furthermore, communication with our patients, thirdparty payers and the public also faces these same challenges.

The primary purpose of this consensus is to provide a clear and useable reference for anyone using musculoskeletal and sports ultrasound. We aim to improve the clarity of communication in clinical practice and improve consistency in the literature. While other terminology references are
Table 1 General definitions

\begin{tabular}{|c|c|}
\hline Term & Definition \\
\hline Musculoskeletal ultrasound & $\begin{array}{l}\text { The use of ultrasound to diagnose and/or guide treatment of conditions involving bones, joints, tendons, } \\
\text { muscles, bursae, ligaments, cartilage, nerves, fascia and related soft tissue structures. Indications and } \\
\text { specifications are outlined in the AIUM Practice Parameter for the Performance of a Musculoskeletal } \\
\text { Ultrasound Examination, }{ }^{6} \text { the AIUM Practice Parameter for the Performance of Selected Ultrasound- } \\
{\text { Guided Procedures }{ }^{7} \text { and the ESSR Musculoskeletal Ultrasound Technical Guidelines. }}^{8}\end{array}$ \\
\hline Sports ultrasound & $\begin{array}{l}\text { The use of ultrasound by a qualified medical professional to diagnose and/or guide treatment for } \\
\text { injuries and medical conditions associated with sport and exercise. This may involve both clinical and } \\
\text { in-the-field applications. Sports ultrasound evaluations are most often performed to answer a specific } \\
\text { clinical question, and the need for further imaging or involvement of other medical imaging experts } \\
\text { should be considered. }\end{array}$ \\
\hline
\end{tabular}

AIUM, American Institute of Ultrasound in Medicine; ESSR, European Society of Musculoskeletal Radiology; SSR, Society of Skeletal Radiology 


\begin{tabular}{|c|c|}
\hline Term & Definition \\
\hline \multicolumn{2}{|l|}{ Equipment } \\
\hline Transducer & The hand-held device with which one obtains ultrasound images \\
\hline Cord & $\begin{array}{l}\text { The connection of the hand-held ultrasound device to the } \\
\text { machine or viewing device (if not wireless) }\end{array}$ \\
\hline \multicolumn{2}{|c|}{ Transducer manipulation } \\
\hline Slide & Motion of the transducer across the body surface in any direction \\
\hline Heel-toe & $\begin{array}{l}\text { Motion in the long axis of the transducer along a fixed point } \\
\text { changing the angle of insonation away from } 90^{\circ} \text { to the skin } \\
\text { surface while maintaining contact with the skin surface, often } \\
\text { used to achieve an angle of insonation at } 90^{\circ} \text { to the target } \\
\text { structure to optimise visualisation and eliminate anisotropy }\end{array}$ \\
\hline Tilt & $\begin{array}{l}\text { Motion in the short axis of the transducer along a fixed point } \\
\text { changing the angle of insonation away from } 90^{\circ} \text { to the skin } \\
\text { surface while maintaining contact with the skin surface, often } \\
\text { used to achieve an angle of insonation at } 90^{\circ} \text { to the target } \\
\text { structure to optimise visualisation and eliminate anisotropy }\end{array}$ \\
\hline Compression & $\begin{array}{l}\text { Force is applied by the sonographer or sonologist on the } \\
\text { transducer towards the patient's body. }\end{array}$ \\
\hline Rotation & $\begin{array}{l}\text { Motion along a fixed centre axis point of the transducer in the } \\
\text { clockwise or counterclockwise direction }\end{array}$ \\
\hline Pivot & $\begin{array}{l}\text { Motion along a fixed axis point at the end of the transducer in } \\
\text { the clockwise or counterclockwise direction }\end{array}$ \\
\hline Stand off & $\begin{array}{l}\text { The transducer does not touch the skin surface but rests on a } \\
\text { layer of acoustic coupling gel or other acoustic medium with } \\
\text { angle of insonation at } 90^{\circ} \text { to the skin surface. }\end{array}$ \\
\hline Oblique stand off & $\begin{array}{l}\text { The transducer does not touch the skin surfacebut rests on a } \\
\text { layer of acoustic coupling gel or other acoustic medium with } \\
\text { angle of insonation away from } 90^{\circ} \text { to the skin surface. }\end{array}$ \\
\hline Sonopalpation & $\begin{array}{l}\text { Force is applied on the transducer towards the patient's body to } \\
\text { elicit symptom provocation (eg, pain). }\end{array}$ \\
\hline
\end{tabular}

available, our focus was on clinically relevant topics in the context of musculoskeletal medicine, where we identified frequent variations in terminology used in everyday practice, scientific presentations and the literature. Our goal was to present a user-friendly reference of the most common terminology encountered in musculoskeletal and sports ultrasound.

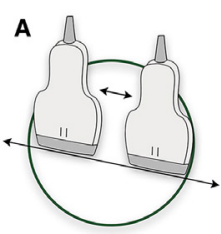

D

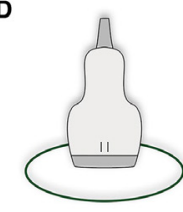

$\mathbf{F}$

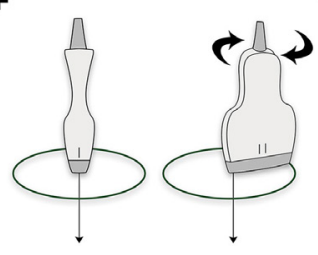

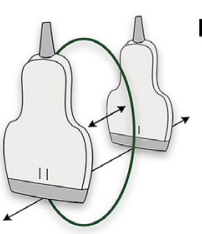
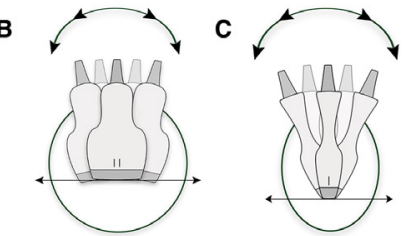

E
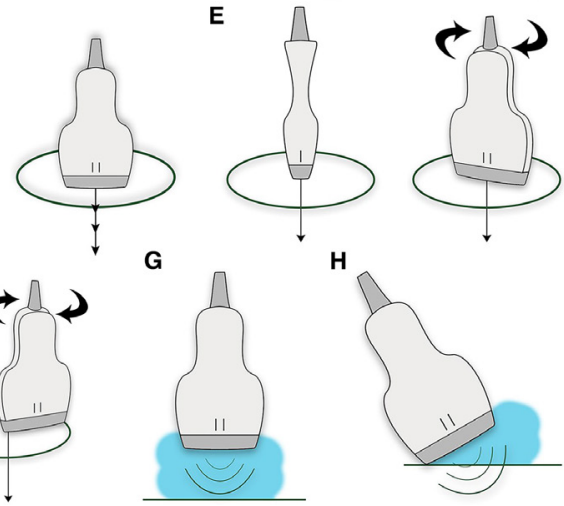

H

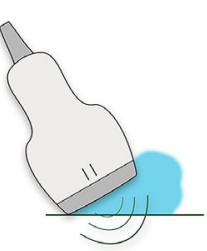

Figure 1 (A) Slide, (B) heel-toe, (C) tilt, (D) compression, (E) rotation, (F) pivot, (G) stand-off and (H) oblique stand-off.

Table 3 Anatomical and descriptive terms*

\begin{tabular}{ll}
\hline Term & Definition \\
\hline Body planes & $\begin{array}{l}\text { Anatomical region (eg, knee) when displayed in cross- } \\
\text { section to the region }\end{array}$ \\
\hline Transverse & $\begin{array}{l}\text { Anatomical region (eg, knee) when displayed parallel to } \\
\text { the region lengthwise; when used to refer to an anatomical } \\
\text { region, may refer to either the coronal or sagittal plane }\end{array}$ \\
\hline Longitudinal & $\begin{array}{l}\text { Any plane perpendicular to a sagittal plane and parallel to } \\
\text { the long axis of the body; each coronal image plane extends } \\
\text { from left to right through the body. }\end{array}$ \\
\hline $\begin{array}{l}\text { Coronal (frontal) imang } \\
\text { plane }\end{array}$ & $\begin{array}{l}\text { The anteroposterior plane parallel to the long axis of the } \\
\text { body and passing through the midline; anteroposterior } \\
\text { planes not passing through the centre of the body are } \\
\text { frequently called parasagittal planes. }\end{array}$ \\
\hline Sagittal image plane & $\begin{array}{l}\text { A plane perpendicular to the long axis of the body or } \\
\text { structure of interest; with respect to the body, a transverse } \\
\text { plane extends from left to right and divides the body into } \\
\text { superior and inferior regions. }\end{array}$ \\
\hline Transverse image \\
plane
\end{tabular}

${ }^{*}$ All anatomical terms are defined with the body in the anatomical position.

\section{METHODS}

\section{Expert group selection and demographics}

The project was approved by the board of directors of the American Institute of Ultrasound in Medicine (AIUM) and the American Medical Society for Sports Medicine (AMSSM) who served as the lead societies for this article. Members were invited to represent a diverse group of physicians with experience in the musculoskeletal and sports medicine applications of ultrasound. The AIUM and AMSSM reached out to multiple societies identified to be key stakeholders with the following societies contributing members: American Academy of Orthopaedic Surgeons, American Academy of Physical Medicine \& Rehabilitation, American Orthopaedic Society for Sports Medicine, American Society of Regional Anaesthesia and Pain Medicine, European Society of Musculoskeletal Radiology, Society of Interventional Radiology and Society of Skeletal Radiology. Primary specialties represented include anaesthesia, emergency medicine, family medicine, physical medicine and rehabilitation, orthopaedic surgery and radiology. 
Consensus statement

\begin{tabular}{|c|c|}
\hline Term & Definition \\
\hline \multicolumn{2}{|l|}{ (A) Tendon } \\
\hline Tendinopathy ${ }^{9-12}$ & $\begin{array}{l}\text { A clinical term used to describe painful conditions of the } \\
\text { tendon or tendon sheath including tendinosis, tendinitis } \\
\text { and tendon tear }\end{array}$ \\
\hline Tendinosis $^{911-14}$ & $\begin{array}{l}\text { A chronic tendon condition characterised histologically } \\
\text { as collagen degeneration (predominantly mucoid) with } \\
\text { other variable features such as collagen disorganisation, } \\
\text { fibrocartilaginous metaplasia, calcification and possible } \\
\text { neovascularity; primarily an overused and degenerative } \\
\text { process with absence of an acute inflammatory infiltrate, } \\
\text { but inflammatory mediators may be present }\end{array}$ \\
\hline Tendinitis $^{91112}$ & Tendon inflammation. \\
\hline
\end{tabular}

Calcific tendinopathy ${ }^{1516} \begin{aligned} & \text { Calcium deposition within a tendon; if calcium } \\ & \text { hydroxyapatite, this may be termed calcific tendinosis. Use } \\ & \text { calcific tendinitis when in the resorptive or inflammatory } \\ & \text { stage. }\end{aligned}$
Tenosynovitis $^{912}$

$\begin{array}{ll}\text { Stenosing tenosynovitis }^{9}{ }^{9} 1718 & \begin{array}{l}\text { A subtype of tenosynovitis that affects tendons that course } \\ \text { through osteofibrous tunnels composed of bone covered } \\ \text { by a pulley or retinaculum. The hallmark is thickening } \\ \text { of the pulley or retinaculum that causes constriction. } \\ \text { Examples include trigger finger and de Quervain } \\ \text { tenosynovitis. }\end{array} \\ \text { Paratenonitis }^{919-21} & \begin{array}{l}\text { Inflammation and fibrosis of the paratenon surrounding a } \\ \text { tendon that does not have a tenosynovial sheath (ie, the } \\ \text { Achilles tendon) }\end{array}\end{array}$

$\begin{array}{ll}\text { Tear }^{22-25} & \begin{array}{l}\text { Disruption of tendon, categorised as partial thickness } \\ \text { (interstitial/intrasubstance, bursal or articular (if } \\ \text { relevant)) or full thickness (focal or full width/complete); } \\ \text { a longitudinal split tear may also be described, typically } \\ \text { when involving a tubular tendon. }\end{array} \\ \text { Avulsion } & \begin{array}{l}\text { Tendon tear at its bony attachment or a fracture at a } \\ \text { tendon attachment }\end{array} \\ \text { (B) Muscle } & \begin{array}{l}\text { A clinical/biomechanical term which is not well defined } \\ \text { and used inconsistently for different muscle injuries }\end{array} \\ \text { Strain }^{26} & \text { Injury to muscle fibres or internal aponeuroses } \\ \text { Tear }^{26-31} & \\ & \text { Muscle injury with or without haematoma most commonly } \\ \text { as a result of blunt trauma }\end{array}$

Myositis ossificans s $^{272} 33$ A subtype of heterotopic ossification located within muscle Hyperechoic in early phase followed by a hypoechoic massmost commonly occurring after trauma, often preceded by like area within muscle, with hyperechoic foci maturing haematoma communicate with joints (ie, long head
Ultrasound appearance

Caveat

The use of a more precise term is recommended when describing imaging findings if possible.

Abnormally hypoechoic tendon without tendon fibre disruption, with possible increase in tendon diameter, with or without flow on Doppler imaging (figure 2A)
Abnormally hypoechoic tendon occasionally associated with possible increased flow on Doppler imaging
Imaging features of tendinosis and tendinitis are similar and may be difficult to differentiate. Features of tendinosis and tendinitis may be present concurrently. Hyperaemia, as seen in tendinosis, is due to neovascularity and should not be equated with acute inflammation. Clinical features (such as history of inflammatory disease) may be required to determine the most likely histological diagnosis.

Calcium hydroxyapatite appears as a globular welldefined hyperechoic focus within a tendon with variable shadowing. Overlap with other forms of calcification and crystal deposition are possible. Small punctate or linear tendon calcifications may also be due to calcium pyrophosphate dihydrate deposition disease or degenerative calcification. Amorphous echogenicity with variable shadowing can be seen with monosodium urate deposition in gout (figure 2B).

Distention of a tendon sheath from fluid of variable echogenicity with or without synovial hypertrophy and possible increased flow on Doppler imaging (figure $2 \mathrm{C}$

Some tendon sheaths normally of the biceps brachii tendon sheath and glenohumeral joint, flexor hallucis longus tendon sheath and tibiotalar joint). Simple fluid within the tendon sheath may be secondary to intra-articular pathology rather than tenosynovitis.

Hypoechoic thickening of pulley or retinaculum with possible hyperaemia on Doppler imaging with possible additional findings of tendinosis and tenosynovitis (figure 2D)

Focal or diffuse abnormal hypoechogenicity surrounding a tendon with possible increased flow on Doppler imaging (figure 2E)

Hypoechoic or anechoic tendon fibre disruption with an extent defined by the categories listed in the definition column. With longitudinal tears, the hypoechoic or anechoic abnormality is parallel to the long axis of the tendon (figure 2F).

Variable depending on specific pathology (see other more precise terms)

Due to a traction mechanism (as opposed to direct trauma)

Generally, refers to an elongation or stretch type of injury

Numerous clinical and imaging-based classification and grading systems for muscle injury exist. musculotendinous disruption (partial or complete) with possible haemorrhage of variable echogenicity. Possible increased flow on Doppler imaging (figure 3A.1,A.2)

Several related terms have been described peritenonitis and peritendinitis, paratenopathy, among others.

Mixed echogenicity area of muscle fibre disruption ranging from hyperechoic when acute to anechoic when chronic with possible mass effect from haematoma, possible like area within muscle, with hyperechoic foci maturing shadowing. Possible increased flow on Doppler imaging (figure 3C)
Radiograph or CT scan may be required to confirm the peripheral mineralisation when shadowing does not allow accurate characterisation 
Consensus statement

\begin{tabular}{|c|c|c|c|}
\hline Term & Definition & Ultrasound appearance & Caveat \\
\hline Myositis $^{34}$ & $\begin{array}{l}\text { Muscle inflammation including idiopathic, autoimmune, } \\
\text { and infectious aetiologies with possible superimposed } \\
\text { abscess in the latter (see pyomyositis) }\end{array}$ & $\begin{array}{l}\text { Increased muscle echogenicity and possible distortion of } \\
\text { the muscle architecture with increased muscle size when } \\
\text { acute and variable increased flow on Doppler imaging; } \\
\text { other conditions such as rhabdomyolysis may have a } \\
\text { similar appearance. }\end{array}$ & \\
\hline Pyomyositis $^{3536}$ & Muscle abscess & $\begin{array}{l}\text { Circumscribed heterogeneous fluid collection ranging } \\
\text { from anechoic to hyperechoic with increased through } \\
\text { transmission and commonly peripheral increased flow on } \\
\text { Doppler imaging }\end{array}$ & $\begin{array}{l}\text { Clinical features may help in differentiating } \\
\text { from other causes of fluid collection within } \\
\text { a muscle. }\end{array}$ \\
\hline Fatty Infiltration ${ }^{34}$ & $\begin{array}{l}\text { Fat infiltration of muscle from disuse, dysfunction, injury or } \\
\text { denervation, among other causes, with the term atrophy } \\
\text { used when muscle is also decreased in size. }\end{array}$ & $\begin{array}{l}\text { Diffuse increased muscle echogenicity with possible } \\
\text { decrease in muscle size when atrophic (figure 3D) }\end{array}$ & \\
\hline \multicolumn{4}{|l|}{ (C) Ligament } \\
\hline Sprain $^{3738}$ & $\begin{array}{l}\text { A clinical/biomechanical term, which is not well defined } \\
\text { and used inconsistently for different ligament injuries }\end{array}$ & Depends on severity of injury & $\begin{array}{l}\text { Generally, refers to an elongation or } \\
\text { stretch type of injury }\end{array}$ \\
\hline $\mathrm{Tear}^{3738}$ & $\begin{array}{l}\text { Injury to ligament fibres which may include partial or } \\
\text { complete ligament disruption }\end{array}$ & $\begin{array}{l}\text { Partial or complete ligament disruption with variable } \\
\text { degrees of laxity on stress imaging based on severity of } \\
\text { injury; echogenicity and ligament thickness are variable; } \\
\text { possible increased flow on Doppler imaging (figure } 4 A, B \text { ) }\end{array}$ & $\begin{array}{l}\text { Numerous clinical and imaging-based } \\
\text { classification and grading systems for } \\
\text { specific ligament injuries exist. }\end{array}$ \\
\hline Avulsion & $\begin{array}{l}\text { Ligament tear at its bony attachment or a fracture at a } \\
\text { ligament attachment. }\end{array}$ & $\begin{array}{l}\text { Variable, depending on specific pathology (see other more } \\
\text { precise terms) }\end{array}$ & $\begin{array}{l}\text { Due to a traction mechanism (as opposed } \\
\text { to direct trauma) }\end{array}$ \\
\hline \multicolumn{4}{|c|}{ (D) Joint recess, bursa and tendon sheath } \\
\hline Term & Definition & Ultrasound appearance & \\
\hline Effusion $^{39-42}$ & $\begin{array}{l}\text { Distention of a synovial space with fluid from several } \\
\text { possible aetiologies, including but not limited to, } \\
\text { mechanical, reactive, and inflammatory mechanisms, } \\
\text { among others }\end{array}$ & $\begin{array}{l}\text { Fluid distention of a synovial space of variable echogenicity } \\
\text { depending on composition (figure } 5 \mathrm{~A} \text { ) }\end{array}$ & \\
\hline Synovial hypertrophy ${ }^{39-41}$ & $\begin{array}{l}\text { Thickened synovium characteristic of several aetiologies, } \\
\text { including, but not limited to, mechanical, reactive, } \\
\text { and inflammatory (infection or inflammatory arthritis) } \\
\text { mechanisms. }\end{array}$ & $\begin{array}{l}\text { Variable echogenicity (most commonly hypoechoic) } \\
\text { non-compressible or minimally compressible tissue with } \\
\text { variable flow on Doppler imaging; increased blood flow } \\
\text { could indicate active inflammation (termed synovitis as } \\
\text { described below). }\end{array}$ & \\
\hline Synovial proliferation ${ }^{43}$ & $\begin{array}{l}\text { Thickened synovium due to several non-inflammatory } \\
\text { etiologies, such as pigmented villonodular synovitis, lipoma } \\
\text { arborescens and synovial chondromatosis (which is often } \\
\text { mineralised). }\end{array}$ & $\begin{array}{l}\text { Variable echogenicity non-compressible or minimally } \\
\text { compressible synovial thickening or mass-like appearance } \\
\text { with variable flow on Doppler imaging (figure 5B) }\end{array}$ & \\
\hline Synovitis ${ }^{39-41} 44$ & $\begin{array}{l}\text { Inflammation of the synovium within a joint recess, tendon } \\
\text { sheath or anatomic bursa; use a more specific term (eg, } \\
\text { tenosynovitis) whenever possible. }\end{array}$ & $\begin{array}{l}\text { Variable echogenicity (most commonly hypoechoic) } \\
\text { synovial tissue that is not displaceable and minimally } \\
\text { compressible with possible increased flow on Doppler } \\
\text { imaging (figure 5C) }\end{array}$ & \\
\hline Bursitis $^{45}$ & Inflammation of bursa & $\begin{array}{l}\text { Variable, depending on the underlying pathology, which } \\
\text { can include effusion, synovial hypertrophy, synovial } \\
\text { proliferation and synovitis with possible increased flow on } \\
\text { Doppler imaging }\end{array}$ & \\
\hline \multicolumn{4}{|l|}{ (E) Nerve } \\
\hline Neuropathy & A term that encompasses several nerve conditions & Variable, depending on specific pathological process & $\begin{array}{l}\text { The use of a more precise term is } \\
\text { recommended when describing imaging } \\
\text { findings if possible. }\end{array}$ \\
\hline $\begin{array}{l}\text { Compression } \\
\text { neuropathy } y^{46-48}\end{array}$ & $\begin{array}{l}\text { Disorder characterised by nerve dysfunction as a result of } \\
\text { nerve entrapment or extrinsic impingement }\end{array}$ & $\begin{array}{l}\text { Hypoechoic appearance of nerve from epineural oedema } \\
\text { with possible fascicular enlargement typically proximal and } \\
\text { sometimes distal to the compression site (figure } 6 \mathrm{~A} \text { ) }\end{array}$ & $\begin{array}{l}\text { Nerve compression first results in oedema } \\
\text { followed by demyelination and then } \\
\text { ischaemic axonal damage when the } \\
\text { compression is severe and chronic }\end{array}$ \\
\hline Transection $^{49}$ & $\begin{array}{l}\text { Partial or complete discontinuity of a nerve due to } \\
\text { disruption of some or all the nerve fascicles }\end{array}$ & $\begin{array}{l}\text { Discontinuity of some or all nerve fascicles with possible } \\
\text { retraction of the discontinuous nerve and focal or mass-like } \\
\text { thickening at the retracted end (see neuroma) (figure 6B) }\end{array}$ & \\
\hline Neuroma ${ }^{49} 50$ & $\begin{array}{l}\text { The focal enlargement of an injured nerve or fascicle, } \\
\text { which may be associated with nerve or fascicular } \\
\text { retraction if due to transection }\end{array}$ & $\begin{array}{l}\text { Hypoechoic focal nerve or fascicle enlargement at the site } \\
\text { of injury with possible retraction (figure } 6 C \text { ) }\end{array}$ & \\
\hline Neuritis ${ }^{51}$ & $\begin{array}{l}\text { Nerve inflammation as seen with inflammatory, infectious } \\
\text { or autoimmune conditions }\end{array}$ & $\begin{array}{l}\text { Abnormally hypoechoic nerve with possible increased flow } \\
\text { on Doppler imaging }\end{array}$ & \\
\hline \multicolumn{4}{|l|}{ (F) Fascia } \\
\hline Fasciopathy ${ }^{52} 53$ & A term that encompasses several fascial conditions & Variable, depending on the specific pathological process & $\begin{array}{l}\text { The use of a more precise term is } \\
\text { recommended when describing imaging } \\
\text { findings if possible. }\end{array}$ \\
\hline Fasciosis $^{5253}$ & $\begin{array}{l}\text { A chronic condition characterised histologically as } \\
\text { degeneration, collagen necrosis, angiofibrotic hyperplasia, } \\
\text { chondroid metaplasia and fibrosis; although primarily } \\
\text { a degenerative process from mechanical overload with } \\
\text { absence of an acute inflammatory infiltrate, inflammatory } \\
\text { mediators may be present. }\end{array}$ & $\begin{array}{l}\text { Hypoechoic thickening of the fascia with possible } \\
\text { calcification and possible increased flow on Doppler } \\
\text { imaging (figure 7) }\end{array}$ & \\
\hline
\end{tabular}


Table 4 Continued

\begin{tabular}{lll}
\hline Term & Definition & Ultrasound appearance \\
\hline Fasciitis & Inflammation of fascia & $\begin{array}{l}\text { Hypoechoic thickening of the fascia with possible increased } \\
\text { flow on Doppler imaging }\end{array}$ \\
Tear & $\begin{array}{l}\text { Injury to fascial fibres which may include partial or } \\
\text { complete disruption }\end{array}$ & $\begin{array}{l}\text { Partial or complete disruption with variable echogenicity } \\
\text { and thickness and possible haemorrhage of variable } \\
\text { echogenicity; there may be loss of tension with complete } \\
\text { disruption; possible increased flow on Doppler imaging }\end{array}$
\end{tabular}

\begin{tabular}{|c|c|c|}
\hline \multicolumn{3}{|l|}{ (G) Bone } \\
\hline Osteophyte & $\begin{array}{l}\text { A bony excrescence at the margin of a synovial articulation } \\
\text { as a manifestation of osteoarthritis (or osteoarthrosis) }\end{array}$ & $\begin{array}{l}\text { Hyperechoic bony excrescence typically at the margin of a } \\
\text { synovial articulation }\end{array}$ \\
\hline Enthesophyte & $\begin{array}{l}\text { A bony excrescence at a tendon, ligament or fascia } \\
\text { attachment, typically as a manifestation of overuse, } \\
\text { tension, prior injury or adjacent tendinosis (when well } \\
\text { defined) or inflammation (when ill-defined with possible } \\
\text { erosions termed enthesitis or inflammatory enthesopathy) }\end{array}$ & $\begin{array}{l}\text { Hyperechoic bony excrescence at a tendon, ligament or } \\
\text { fascia attachment; } \\
\text { may be well defined or ill-defined with possible associated } \\
\text { erosions and possible increased flow on Doppler imaging }\end{array}$ \\
\hline Erosion $^{40}$ & $\begin{array}{l}\text { Cortical discontinuity in a subsynovial or enthesis location, } \\
\text { a manifestation of inflammation (infection or inflammatory } \\
\text { arthritis) with possible associated synovial hypertrophy }\end{array}$ & $\begin{array}{l}\text { Discontinuity of the hyperechoic cortical bone surface in a } \\
\text { subsynovial or enthesis location confirmed in two planes, } \\
\text { may have associated synovial hypertrophy (see previously } \\
\text { mentioned definition) and possible increased flow on } \\
\text { Doppler imaging }\end{array}$ \\
\hline \multicolumn{3}{|c|}{ (H) Miscellaneous } \\
\hline Term & \multicolumn{2}{|c|}{ Definition } \\
\hline Hyperaemia & \multicolumn{2}{|c|}{ Increased blood flow due to neovascularity (as seen in tendinosis and tumours) and/or vasodilation due to inflammation (as in inflammatory synovitis or infection). } \\
\hline Subluxation & \multicolumn{2}{|c|}{$\begin{array}{l}\text { When a structure is partially displaced from its normal anatomical location, possibly only occurring with dynamic manoeuvres (ie, dynamic subluxation); the word } \\
\text { 'sublux' and 'subluxed' do not exist in the English dictionary and should be avoided in favour of subluxate and subluxation. }\end{array}$} \\
\hline Dislocation & \multicolumn{2}{|c|}{ When a structure is completely displaced from its normal anatomical location, including those occurring with dynamic manoeuvres (ie, dynamic dislocation) } \\
\hline
\end{tabular}

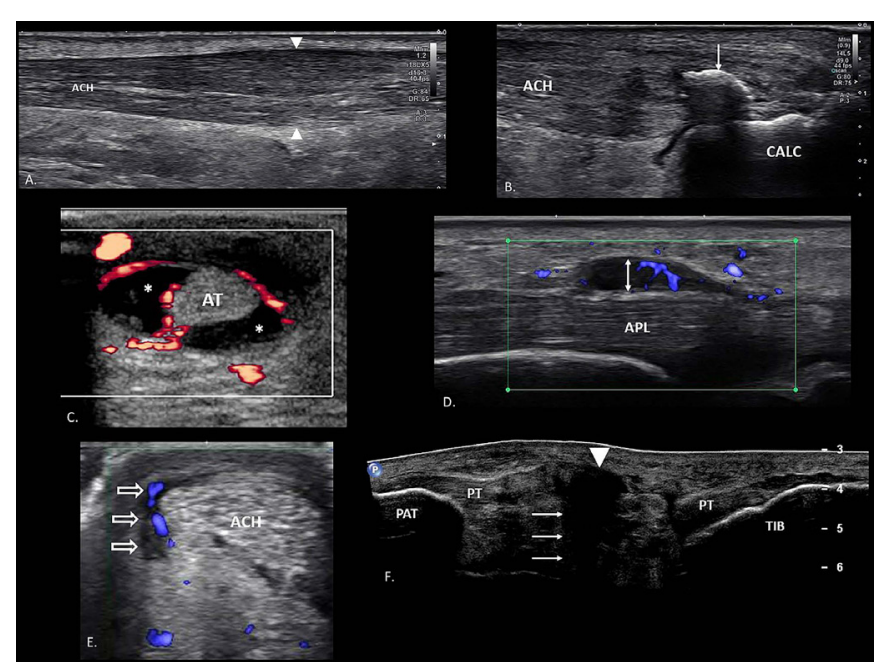

Figure 2 (A) Tendinosis: long-axis image of midportion Achilles tendinosis. Note fusiform thickening (arrowheads) without fibre disruption. (B) Calcific tendinopathy: long-axis image of calcific tendinosis of the ACH insertion. The well-defined hyperechoic focus (arrow) demonstrates intermediate posterior acoustic shadowing. (C) Tenosynovitis: short-axis image of the AT demonstrating distension of the tendon sheath (asterisks) with increased Doppler flow. (D) Stenosing tenosynovitis: long-axis view of the first dorsal compartment of the wrist. The retinaculum (double arrow) is hypoechoic and significantly thickened with hyperaemia on Doppler. (E) Paratenonitis: short axis image of the ACH. There is focal hypoechoic thickening of the lateral aspect of the paratenon (open arrows) with hyperaemia on Doppler. (F) Tendon tear: long-axis extended field of view image of acute PT complete tear. There is loss of tension with a hypoechoic region of tendon fibre disruption (arrowhead). Edge shadowing artefact (arrows) is noted deep to the proximal tendon stump. ACH, Achilles tendon; APL, abductor pollicis longus tendon; AT, anterior tibialis tendon; CALC, calcaneus; PAT, patella; PT, patellar tendon; TIB, tibia.

\section{Preliminary work}

A list of general topics to be included was discussed among the group and organised as presented in box 1. Each section was then assigned to a small working group who was responsible for identifying key references and creating the initial list of terms to be defined. This was circulated among the group until agreement was reached on final terms to be included. Each small group was

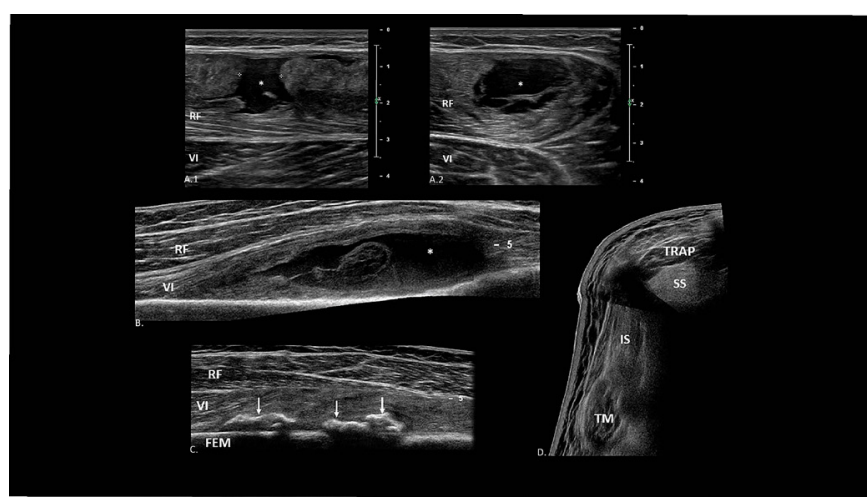

Figure 3 (A) Muscle tear: (1) long-axis image of the RF demonstrating an acute disruption of the central aponeurosis and surrounding muscle (callipers); there is anechoic haemorrhagic fluid (asterisks) at the site of tear; (2) corresponding short-axis image. (B) Muscle contusion: longaxis extended field of view image of an acute quadriceps contusion. Muscle fibre disruption of the VI is noted with a large anechoic haematoma (asterisks) resulting in mass effect. (C) Myositis ossificans: long-axis image of the quadriceps. This follow-up image of the muscle contusion (B) demonstrates resolution of haematoma with formation of hyperechoic regions of myositis ossificans (arrows). (D) Muscle fatty infiltration: short-axis extended field of view image of the rotator cuff musculature in setting of chronic complete rotator cuff tear. The SS and IS are diffusely hyperechoic with loss of internal muscle fibre definition. FEM, femur; IS, infraspinatus; RF, rectus femoris; SS, supraspinatus; TM, teres minor; TRAP, trapezius; VI, vastus intermedius. 


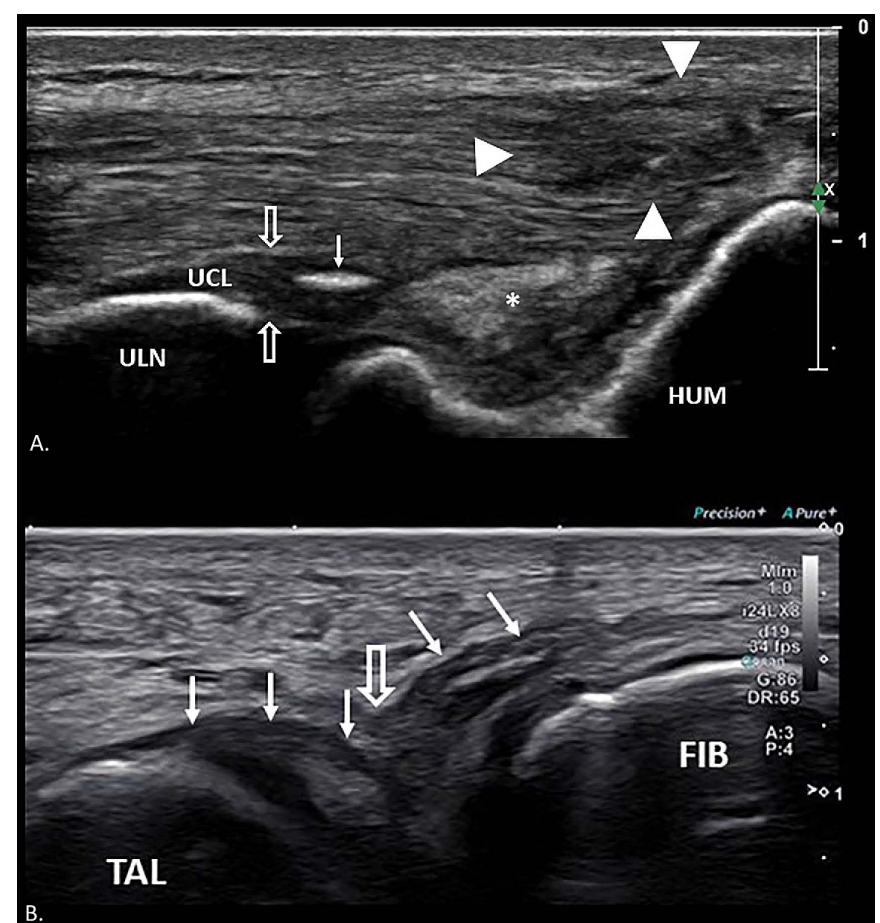

Figure 4 (A) Ligament tear: long-axis image of an acute UCL tear. A hyperechoic region of fibre disruption and haematoma (asterisks) is noted proximal. The distal attachment is intact but thickened (open arrows) and a hyperechoic linear density (solid arrow) overlying the joint space represents chronic calcific changes. Also note an associated muscle injury of the flexor/pronator group (arrowheads). (B) Ligament tear: long-axis image of acute anterior talofibular ligament (arrows) tear. Loss of tension results in an atypical contour of the ligament (open arrow). This can be further confirmed with dynamic stress imaging. FIB, fibula; HUM, humerus; UCL, ulnar collateral ligament; ULN, ulna; TAL, talus.

then responsible for drafting the working definitions. The list of terms, definitions and key references for each section was then

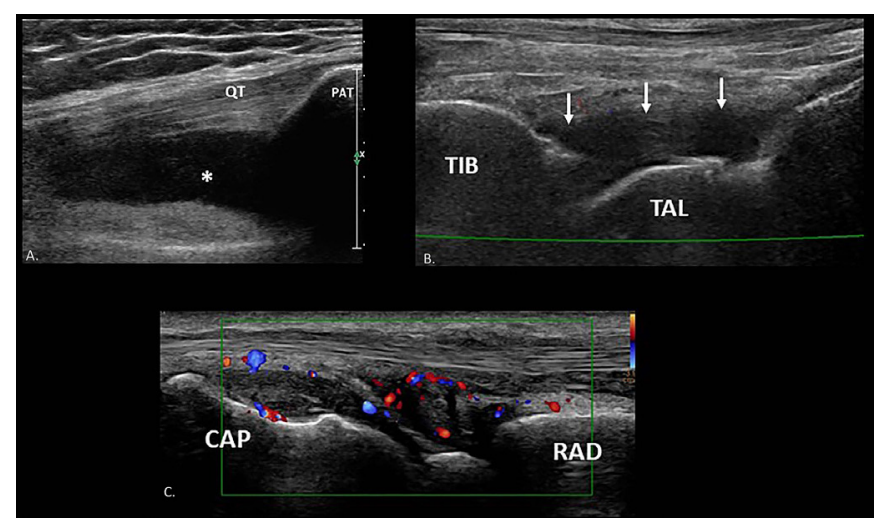

Figure 5 (A) Joint effusion: long-axis image of the suprapatellar recess with anechoic fluid distension (asterisk) representing a simple joint effusion. (B) Synovial proliferation: long-axis image of the anterior ankle with hypoechoic synovial tissue hypertrophy (arrows) without Doppler flow. (C) Synovitis: long-axis image of the dorsal wrist demonstrating hypoechoic synovial tissue with increased Doppler flow in the setting of rheumatoid arthritis. CAP, capitate; RAD, radius; PAT, patella; QT, quadriceps tendon; TAL, talus; TIB, tibia.

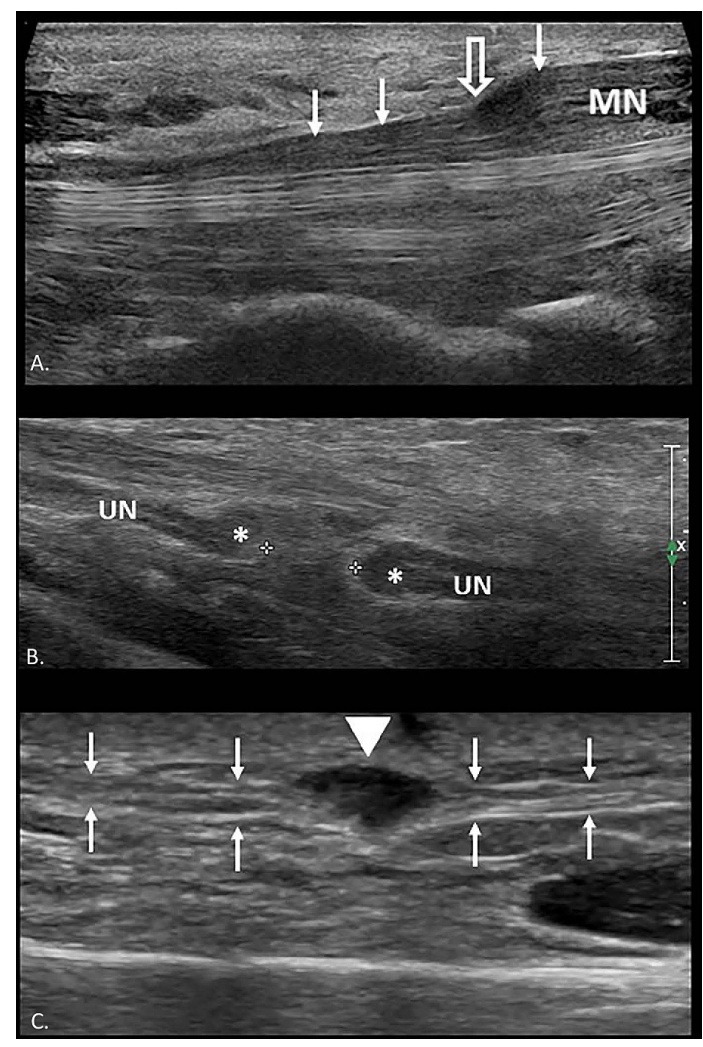

Figure 6 (A) Compression neuropathy: long-axis image of the median nerve (arrows) at the carpal tunnel. Significant swelling is noted proximal to the compression site (open arrow). (B) Nerve transection: long-axis image of complete ulnar nerve transection. Note discontinuity of nerve with retraction (callipers) and thickening at the ends representing stump neuromas (asterisks). (C) Neuroma: long-axis image of a partial transection of the lateral antebrachial cutaneous nerve (arrows). Focal hypoechoic enlargement (arrowhead) represents a neuroma at the site of injury. MN, median nerve; UN, ulnar nerve.

made available to the group for review prior to the initiation of the Delphi procedure.

\section{Delphi procedure}

A Delphi method was used to reduce 'group think' bias by allowing anonymous voting and comments. The group leader $(\mathrm{MMH})$ was responsible for developing and distributing all surveys and moderating discussion among the group. Qualtrics

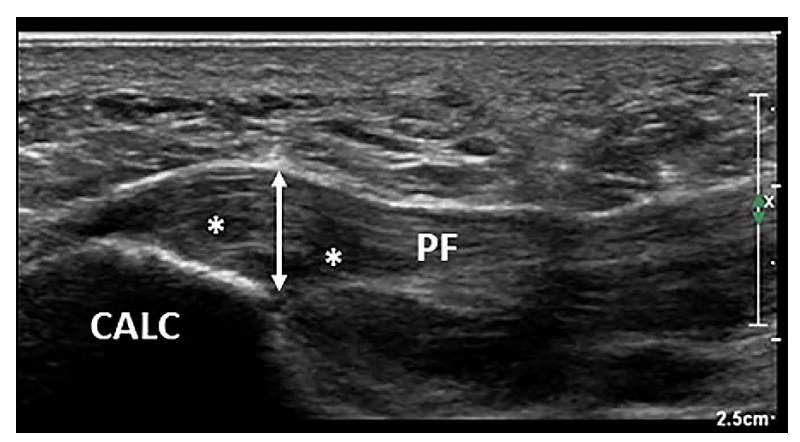

Figure 7 Fasciosis: long-axis image of the plantar fascia. Thickening of the origin is noted (double arrow) with focal hypoechoic regions (asterisks) representing degenerative changes. CALC, calcaneus; PF, plantar fascia. 


\begin{tabular}{|c|c|}
\hline Term & Definition \\
\hline \multicolumn{2}{|l|}{ Needle/device terminology } \\
\hline In-plane ${ }^{55}$ & Needle/device aligned with the long axis of the transducer \\
\hline Out-of-plane $e^{55}$ & Needle/device aligned perpendicular to the long axis of the transducer \\
\hline Jiggling ${ }^{55}$ & Rapid, low-amplitude movement of the needle/device in the plane of insertion to facilitate needle visualisation \\
\hline Rotation $^{55}$ & Rotating the needle will result in the bevel alternately facing up and down, thus enabling identification of the needle tip. \\
\hline Stylet movement ${ }^{55}$ & $\begin{array}{l}\text { Small movements of a stylet in and out of the tip of the needle to improve needle tip visualisation; the stylet should not be modified to allow it to advance beyond } \\
\text { the needle tip when using this technique for visualisation. }\end{array}$ \\
\hline \multicolumn{2}{|l|}{ Procedure technique descriptions } \\
\hline Aponeurotomy ${ }^{5657}$ & Cutting an aponeurosis, either completely or incompletely, using a needle, scalpel or other device. \\
\hline Aspiration & $\begin{array}{l}\text { The act of removing fluid, calcification or other crystalline material, blood, pus or other substance from the body typically using a needle and syringe, catheter or } \\
\text { another device }\end{array}$ \\
\hline Barbotage $^{58}$ & Repeated injection and aspiration of fluid to break up and remove calcification, usually within a tendon \\
\hline Brisement $^{59-61}$ & $\begin{array}{l}\text { The injection of fluid into the space between a tendon and its paratenon or sheath; brisement has also been used to refer to injection of saline or other fluid into a } \\
\text { joint to break down adhesions (eg, in treatment of adhesive capsulitis). }\end{array}$ \\
\hline Debridement $^{62} 63$ & The removal of necrotic, degenerative or infected tissue from a region or given tissue of the body. \\
\hline Dry needling ${ }^{64}$ & $\begin{array}{l}\text { A procedure, generally used as part of manual physical therapy, where a small gauge needle is inserted into a muscle or other soft tissue structure to treat } \\
\text { myofascial pain }\end{array}$ \\
\hline Fasciotomy ${ }^{656}$ & Cutting fascia, either completely or incompletely, using a needle, scalpel or other device \\
\hline Fenestration ${ }^{64}$ & The act of repetitive puncture of a soft tissue structure with a needle or other device \\
\hline Fragmentation $^{67}$ & The use of a needle or other device to break up calcified and/or bony tissue \\
\hline Hydrodissection ${ }^{68-70}$ & Technique by which saline or other sterile fluid is injected to separate tissues or tissue planes from each other \\
\hline Injection & The act of delivering a fluid or other substance into the body, typically using a needle and syringe, catheter or another device. \\
\hline Lavage $^{71}$ & Washing out using saline or other sterile solution; irrigation is an acceptable alternate term. \\
\hline Neurolysis ${ }^{69} 7072-74$ & There are distinct definitions of neurolysis. An appropriate modifier is recommended to clearly describe the procedure performed. \\
\hline Chemical neurolysis & The application of chemical agents to a nerve in order to cause temporary or permanent degeneration of targeted nerve fibres. \\
\hline Hydroneurolysis & The injection of saline or other sterile fluid to free nerves from surrounding tissue/adhesion; the term 'nerve hydrodissection' is an acceptable alternate term. \\
\hline Surgical neurolysis & The surgical freeing of nerves from surrounding tissue/adhesion \\
\hline Physical neurolysis & The application of physical energy (eg, heat or cold) to a nerve in order to cause temporary or permanent degeneration of the targeted nerve fibres \\
\hline Plantar fasciotomy $y^{756}$ & Cutting the plantar fascia, either completely or incompletely, using a needle, scalpel or other device. \\
\hline Tendon scraping ${ }^{77} 78$ & $\begin{array}{l}\text { The process of abrading the surface of a tendon or paratenon with a needle, scalpel, or other device, with the goal of separating the tendon from neovessels, } \\
\text { neonerves and/or adjacent soft tissues. }\end{array}$ \\
\hline Tenotomy ${ }^{6279-82}$ & Cutting tendon tissue, either completely or incompletely, using a needle, scalpel or other device \\
\hline Trigger finger release $\mathrm{e}^{83}$ & Cutting the pulley and associated tendon sheath responsible for the stenosis using a needle, scalpel or other device \\
\hline \multicolumn{2}{|l|}{ Terms to avoid } \\
\hline $\begin{array}{l}\text { Minimally invasive, ultraminimally } \\
\text { invasive and microinvasive }\end{array}$ & $\begin{array}{l}\text { These are relative and imprecise terms without formal definitions. Therefore, their use is not recommended. The exact procedure should be described including } \\
\text { technique and tool(s) used. }\end{array}$ \\
\hline Needling $^{85}$ & $\begin{array}{l}\text { This is an inconsistent term that has been used to describe a range of procedures from dry needling of myofascial trigger points to tenotomy or fasciotomy } \\
\text { procedures. The use of a more precise term is recommended. 'Needling' should only be used in conjunction with 'dry needling' as previously defined. }\end{array}$ \\
\hline Peppering ${ }^{85}$ & $\begin{array}{l}\text { This term has been used to describe a type of fenestration procedure (often involving a tendon) alone or in conjunction with an injection. The use of more precise } \\
\text { terms such as 'tenotomy', 'fasciotomy' or 'fenestration' is recommended. }\end{array}$ \\
\hline Percutaneous & $\begin{array}{l}\text { This term refers to a procedure performed through the skin. Due to lack of specificity associated with this term, its use in isolation is not recommended. Rather, the } \\
\text { exact procedural technique should be described including tool(s) used and approach. }\end{array}$ \\
\hline
\end{tabular}

\section{Box 2 Template for documenting a diagnostic US} examination*

1. Patient's name and other identifying information.

2. Date and time of examination.

3. Ordering provider.

4. Location and contact information of facility in which the diagnostic US was performed.

5. Clinical history/indication.

6. Description of diagnostic US study performed.

- Anatomical location.

- Complete or limited exam.

7. Findings.

8. Impression/conclusion/summary.

*When reporting a diagnostic US, all structures evaluated should be specifically mentioned either in the 'findings' section or elsewhere in the report, even if within normal limits.

US, ultrasound.
XM (Qualtrics, LLC, Provo, Utah, USA), an online survey and data collection tool, was used to create and conduct all surveys. We set a minimum requirement of $>80 \%$ group participation for each round of surveys to be considered valid. Consensus was defined as group level agreement $>80 \%$. Questions not resulting in consensus were revised based on group feedback and incorporated into subsequent surveys until consensus was reached. Each section was addressed separately and carried through completion prior to beginning the next section.

\section{DISCUSSION}

\section{General}

The term musculoskeletal ultrasound has been used extensively, but we were unable to identify a previously published formal definition. The term sports ultrasound has been more recently introduced by the AMSSM. ${ }^{12}$ Although this term has begun to appear more frequently in the literature, a formal definition has yet to be assigned. Table 1 presents our recommended definitions for each term. 


\section{Equipment and transducer manipulation}

When instructing or discussing ultrasound technique, consistency in terminology used to describe transducer movement and manipulation is critical to avoid confusion and to facilitate effective communication. Although prior authors have made recommendations, these have not been universally accepted. ${ }^{34}$ Furthermore, we identified ongoing confusion regarding cardinal movements as well as additional terms relevant to musculoskeletal and sports medicine practice as listed in table 2 . Of note, we concluded that using a single term, 'slide', to describe moving the transducer from point A to point B was most clear. Further directional or anatomical descriptors may need to be added to provide clarity. These terms are discussed as follows and demonstrated in figure 1.

\section{Anatomical and descriptive terminology}

Table 3 lists recommended anatomical and descriptive terms. There was agreement with the imaging plane definitions presented in the AIUM Recommended Ultrasound Terminology document. ${ }^{5}$ When discussing body planes in relation to the anatomical region of interest, the group was unable to arrive at a consensus for a single term to describe parallel longitudinal planes. Either coronal/sagittal or longitudinal were proposed as appropriate terms. Similarly, when discussing axes of the target structure, we could not reach consensus on a single best term. Short axis and transverse can be used interchangeably as can long axis and longitudinal.

\section{Pathology}

Pathology terms have been divided into groups based on anatomical tissue type with consensus recommendations presented in table 4. Representative images demonstrating key terms can be found in figures 2-7. These terms are not meant to be prescriptive but rather represent the current best terms based on the literature and our expert opinion. We recognise that our understanding of pathophysiological processes is in constant evolution, and certain terms may require modifications based on future research. We focused on the accepted ultrasound appearance of common pathologies, recognising that pathognomonic ultrasound findings do not currently exist for all histopathological conditions. Furthermore, certain clinical conditions may be difficult to differentiate based on imaging features alone. Similarly, although Doppler flow is often considered a key imaging finding for some pathological conditions (eg, synovitis, tendinitis, etc), we agreed that, due to variability in both equipment and technique, the presence or absence of Doppler flow should not be an absolute requirement. Rather, we highlight when Doppler flow may be expected and further supports a specific diagnosis.

\section{Procedural}

Like the pathology section, the procedural terms and definitions presented in table 5 attempt to reconcile the historic use of multiple similar terms in the absence of precise definitions. This has resulted in difficulties interpreting clinical outcomes and conveying procedural techniques both to colleagues and third-party payers. Our goal is for these core terms to be used with appropriate technical descriptors bringing more consistency to procedural reporting.

\section{Image labeling}

There was consensus agreement that all ultrasound images should include labels identifying the target structure or region and laterality as appropriate. Other considerations which did not reach consensus but had majority agreement
Box 3 Template for documenting a US-guided interventional procedure

1. Patient's name and other identifying information.

2. Date and time of intervention.

3. Ordering provider.

4. Location and contact information of facility in which the USguided procedure was performed.

5. Clinical history/indication.

6. Technical.

- Device.

- Medications or other administered substances, including lot number, if applicable.

7. Procedure performed (eg, knee joint aspiration, carpal tunnel release, etc).

8. Injection/aspiration/procedure details.

- Informed consent and time-out statements.

- Description of preinjection images.

- Target images.

- At-risk structures.

- Description of procedure.

- Conditions under which procedure was performed (sterile, aseptic, etc).

- Type of anaesthesia.

- Description of approach-in-plane/out-of-plane, long axis or short axis to the target, medial or lateral to the target.

- Description of the procedure performed including names and amounts of medications or other substances used if applicable. Describe any devices used.

- Specimen description, type and amount removed if applicable.

- Blood loss (if applicable).

- Complications.

- How the procedure was tolerated

9. Disposition and follow-up plans.

include (1) orientation of the image relative to the target structure or region (long axis, short axis, etc); (2) directional orientation (medial, lateral, proximal, distal, etc); (3) directional descriptors for cine loops (proximal to distal, medial to lateral, etc).

\section{Documentation}

The templates in boxes 2 and 3 include the key components which should be considered when documenting a diagnostic ultrasound or ultrasound-guided procedure. Notably, they are not meant to replace local institutional guidelines or policies regarding documentation of ultrasound-related services. These recommendations pertain to all billable ultrasound services performed in any setting. If studies are performed as a non-billable service (eg, in the athletic training room), then individual institutional guidelines and standards should be developed regarding documentation and image archiving. If any information populates the electronic medical record or images automatically, it does not need to be included separately in the report.

\section{CONCLUSION}

The historic use of multiple similar terms in the absence of precise definitions has led to confusion when conveying information between colleagues, patients and third-party 
payers. This multidisciplinary expert consensus addresses multiple areas of variability in diagnostic ultrasound imaging and ultrasound-guided procedures related to musculoskeletal and sports medicine. This concise reference should improve clarity and consistency of communication and reporting.

\section{Author affiliations}

'Orthopedics and Rehabilitation, The University of lowa Roy J and Lucille A Carver College of Medicine, lowa City, lowa, USA

${ }^{2}$ Radiology, University of Oxford, Oxford, UK

${ }^{3}$ Radiology, Georgetown University, Washington, DC, USA

${ }^{4}$ Radiology, Henry Ford Hospital, Detroit, Michigan, USA

${ }^{5}$ Orthopedic Surgery, Harvard Medical School, Boston, Massachusetts, USA

${ }^{6}$ Advanced Musculoskeletal Medicine Consultants, Inc, Novelty, Ohio, USA

${ }^{7}$ Department of Sports Medicine, United States Olympic and Paralympic Committee, Colorado Springs, Colorado, USA

${ }^{8}$ Physical Medicine and Rehabilitation, Mayo Clinic, Rochester, Minnesota, USA

${ }^{9}$ Orthopedic Surgery, University of Colorado, Denver, Colorado, USA

${ }^{10}$ Radiology, Rochester General Hospital, Rochester, New York, USA

${ }^{11}$ Orthopedics and Radiology, Essentia Health, Duluth, Minnesota, USA

${ }^{12}$ Radiology, University of Cincinnati, Cincinnati, Ohio, USA

${ }^{13}$ Surgery and Anesthesiology, Northeast Ohio Medical University, Rootstown, Ohio, USA

${ }^{14}$ Radiology, Thomas Jefferson University Sidney Kimmel Medical College,

Philadelphia, Pennsylvania, USA

${ }^{15}$ Physical Medicine and Rehabilitation, University of Pittsburgh Medical Center,

Pittsburgh, Pennsylvania, USA

${ }^{16}$ Emergency Medicine, University of California Davis, Davis, California, USA

${ }^{17}$ IRCCS Istituto Ortopedico Galeazzi, Milano, Italy

${ }^{18}$ Biomedical Sciences for Health, University of Milan, Milano, Italy

${ }^{19}$ Institute of Advanced Ultrasound Guided Procedures, Sonex Health, Inc, Eagan,

Minnesota, USA

${ }^{20}$ Health Sciences, University of Genoa, Genova, Italy

${ }^{21}$ Radiology, IRCCS Ospedale Policlinico San Martino, Genova, Italy

Correction notice This article has been corrected since it published Online First. The endorsed statement has been updated.

Twitter Jon A Jacobson @jjacobsn

Acknowledgements We would like to thank Andrea Ceranic for her contributions to the artwork presented in Figure 1. The following societies have endorsed this statement: American Institute of Ultrasound in Medicine, American Medical Society for Sports Medicine, American Orthopaedic Society for Sports Medicine, American Society of Regional Anesthesia and Pain Medicine, European Society of Musculoskeletal Radiology, Society of Interventional Radiology and Society of Skeletal Radiology. The American Academy of Physical Medicine and Rehabilitation has affirmed the value of the statement.

Contributors All authors were involved in the conception of the work, acquisition and interpretation of data, drafting and revising of the work, and final approval of the submitted version.

Funding The authors have not declared a specific grant for this research from any funding agency in the public, commercial or not-for-profit sectors.

Competing interests $\mathrm{MMH}$ reports personal fees from Tenex Health and Sonex Health and other support from UpToDate, Inc, all outside the submitted work. GMA reports personnel fees from GE outside of the submitted work. PBD reports personal fees from Siemens Ultrasound, outside of the submitted work. JTF reports other support from DEMOS Publishing and Up to Date, and personal fees from COVR Medical, Sanofi and Aim Specialty Health, all outside the submitted work. DH reports personal fees from Sonex Health, outside of the submitted work. LN reports persona fees from Canon Medical Systems and Tenex Health, and other support from Samumed and SonoSim, all outside of the submitted work. JS reports other support from Sonex Health and Tenex Health, all outside the submitted work. LMS reports personal fees from Abiogen, Fidia Pharma Group, Pfizer, Novartis, Janssen Cilag, Esaote and Samsung Medison, and other support from Bracco Imaging Italia, all outside of the submitted work. All remaining authors have no competing interests to disclose.

Patient consent for publication Not applicable.

Ethics approval This study does not involve human participants.

Provenance and peer review Not commissioned; externally peer reviewed.

\section{ORCID iDs}

Mederic M Hall http://orcid.org/0000-0001-6186-1865

Sandra Allison http://orcid.org/0000-0003-1186-8502

\section{REFERENCES}

1 Finnoff JT, Berkoff D, Brennan F. American medical Society for sports medicine recommended sports ultrasound curriculum for sports medicine fellowships. Br J Sports Med 2015;49:145-50.

2 Hall MM, Bernhardt D, Finnoff JT, et al. American medical Society for sports medicine sports ultrasound curriculum for sports medicine fellowships. Br I Sports Med 2021:bjsports-2021-103915.

3 American Institute of Ultrasound in Medicine. AIUM technical bulletin. transducer manipulation. American Institute of ultrasound in medicine. J Ultrasound Med 1999:18:169-75

4 Bahner DP, Blickendorf JM, Bockbrader M, et al. Language of transducer manipulation: Codifying terms for effective teaching. J Ultrasound Med 2016;35:183-8.

5 American Institute of Ultrasound in Medicine. Recommended ultrasound terminology. Laurel, MD: AIUM Publications, 2019.

6 American Institute of Ultrasound in Medicine. AIUM practice parameter for the performance of a musculoskeletal ultrasound examination. 25. Laurel, MD: American Institute of Ultrasound in Medicine, 2017.

7 AIUM practice parameter for the performance of selected ultrasound-guided procedures. J Ultrasound Med 2016;35:1-40.

8 European Society of Musculoskeletal Radiology. Technical guidelines Vienna, Austria: European Society of musculoskeletal radiology, 2010. Available: https://www.essr.org/ subcommittees/ultrasound/ [Accessed 13 Nov 2020].

9 Khan KM, Cook JL, Bonar F, et al. Histopathology of common tendinopathies. update and implications for clinical management. Sports Med 1999:27:393-408.

10 Mosca MJ, Rashid MS, Snelling SJ, et al. Trends in the theory that inflammation plays a causal role in tendinopathy: a systematic review and quantitative analysis of published reviews. BMJ Open Sport Exerc Med 2018;4:e000332.

11 Scott A, Squier K, Alfredson H, et al. Icon 2019: international scientific tendinopathy symposium consensus: clinical terminology. Br I Sports Med 2020;54:260-2.

12 Sharma P, Maffulli N. Tendon injury and tendinopathy: healing and repair. J Bone Joint Surg Am 2005;87:187-202.

13 Millar NL, Murrell GAC, McInnes IB. Inflammatory mechanisms in tendinopathy towards translation. Nat Rev Rheumatol 2017:13:110-22.

14 Rees JD, Stride M, Scott A. Tendons--time to revisit inflammation. Br J Sports Med 2014:48:1553-7.

15 Hackett L, Millar NL, Lam P, et al. Are the symptoms of calcific tendinitis due to Neoinnervation and/or neovascularization? J Bone Joint Surg Am 2016:98:186-92.

16 Uhthoff HK, Loehr JW. Calcific tendinopathy of the rotator cuff: pathogenesis, diagnosis, and management. J Am Acad Orthop Surg 1997;5:183-91.

17 Choi S-J, Ahn JH, Lee Y-J, et al. De Quervain disease: US identification of anatomic variations in the first extensor compartment with an emphasis on subcompartmentalization. Radiology 2011:260:480-6.

18 Vuillemin V, Guerini H, Bard H, et al. Stenosing tenosynovitis. J Ultrasound 2012;15:20-8.

19 Paavola M, Järvinen TAH. Paratendinopathy. Foot Ankle Clin 2005; 10:279-92.

20 Aström M, Gentz CF, Nilsson P, et al. Imaging in chronic Achilles tendinopathy: a comparison of ultrasonography, magnetic resonance imaging and surgical findings in 27 histologically verified cases. Skeletal Radiol 1996:25:615-20.

21 Stecco A, Busoni F, Stecco C, et al. Comparative ultrasonographic evaluation of the Achilles paratenon in symptomatic and asymptomatic subjects: an imaging study. Surg Radiol Anat 2015;37:281-5.

22 Kumar Y, Alian A, Ahlawat S, et al. Peroneal tendon pathology: pre- and post-operative high resolution US and MR imaging. Eur J Radiol 2017:92:132-44.

23 Millstein ES, Snyder SJ. Arthroscopic management of partial, full-thickness, and complex rotator cuff tears: indications, techniques, and complications. Arthroscopy 2003;19 Suppl 1:189-99.

24 Morag Y, Jacobson JA, Miller B, et al. Mr imaging of rotator cuff injury: what the clinician needs to know. Radiographics 2006;26:1045-65.

25 Schaeffeler C, Mueller D, Kirchhoff C, et al. Tears at the rotator cuff footprint: prevalence and imaging characteristics in $305 \mathrm{Mr}$ arthrograms of the shoulder. Eur Radiol 2011;21:1477-84.

26 Mueller-Wohlfahrt H-W, Haensel L, Mithoefer K, et al. Terminology and classification of muscle injuries in sport: the Munich consensus statement. Br J Sports Med 2013:47:342-50.

27 Blankenbaker DG, Tuite MJ. Temporal changes of muscle injury. Semin Musculoskelet Radiol 2010;14:176-93.

28 Grassi A, Quaglia A, Canata GL, et al. An update on the grading of muscle injuries: a narrative review from clinical to comprehensive systems. Joints 2016:4:039-46.

29 Peetrons P. Ultrasound of muscles. Eur Radiol 2002;12:35-43.

30 Longo V, Jacobson JA, Fessell DP, et al. Ultrasound findings of delayed-onset muscle soreness. J Ultrasound Med 2016:35:2517-21.

31 Pollock N, James SLJ, Lee JC, et al. British athletics muscle injury classification: a new grading system. Br J Sports Med 2014;48:1347-51.

32 Kwee RM, Kwee TC. Calcified or ossified benign soft tissue lesions that may simulate malignancy. Skeletal Radiol 2019:48:1875-90. 
33 Flores DV, Mejía Gómez C, Estrada-Castrillón M, et al. Mr imaging of muscle trauma: anatomy, biomechanics, pathophysiology, and imaging appearance. Radiographics 2018;38:124-48.

34 Adler RS, Garofalo G. Ultrasound in the evaluation of the inflammatory myopathies. Curr Rheumatol Rep 2009;11:302-8.

35 Hayeri MR, Ziai P, Shehata ML, et al. Soft-Tissue infections and their imaging mimics: from cellulitis to necrotizing fasciitis. Radiographics 2016;36:1888-910.

36 Turecki MB, Taljanovic MS, Stubbs AY, et al. Imaging of musculoskeletal soft tissue infections. Skeletal Radiol 2010;39:957-71.

37 Khoury V, Guillin R, Dhanju J, et al. Ultrasound of ankle and foot: overuse and sports injuries. Semin Musculoskelet Radiol 2007;11:149-61.

38 Peetrons P, Creteur V, Bacq C. Sonography of ankle ligaments. J Clin Ultrasound 2004;32:491-9.

39 Taljanovic MS, Melville DM, Gimber LH, et al. High-Resolution us of rheumatologic diseases. Radiographics 2015;35:2026-48.

40 Wakefield RJ, Balint PV, Szkudlarek M, et al. Musculoskeletal ultrasound including definitions for ultrasonographic pathology. J Rheumatol 2005;32:2485-7.

41 D'Agostino M-A, Terslev L, Aegerter P, et al. Scoring ultrasound synovitis in rheumatoid arthritis: a EULAR-OMERACT ultrasound taskforce-Part 1: definition and development of a standardised, consensus-based scoring system. RMD Open 2017;3:e000428.

42 Silva F, Adams T, Feinstein J, et al. Trochanteric bursitis: refuting the myth of inflammation. J Clin Rheumatol 2008;14:82-6.

43 O'Connell JX. Pathology of the synovium. Am J Clin Pathol 2000;114:773-84.

44 Bruyn GA, lagnocco A, Naredo E, et al. OMERACT definitions for ultrasonographic pathologies and elementary lesions of rheumatic disorders 15 years on. J Rheumatol 2019;46:1388-93.

45 Ranganath VK, Hammer HB, McQueen FM. Contemporary imaging of rheumatoid arthritis: clinical role of ultrasound and MRI. Best Pract Res Clin Rheumatol 2020:34:101593.

46 Jung J, Hahn P, Choi B, et al. Early surgical decompression restores neurovascular blood flow and ischemic parameters in an in vivo animal model of nerve compression injury. J Bone Joint Surg Am 2014;96:897-906.

47 Chari B, McNally E. Nerve entrapment in ankle and foot: ultrasound imaging. Semin Musculoskelet Radiol 2018;22:354-63.

48 Klauser AS, Buzzegoli T, Taljanovic MS, et al. Nerve entrapment syndromes at the wrist and elbow by sonography. Semin Musculoskelet Radiol 2018;22:344-53.

49 Tagliafico A, Altafini L, Garello I, et al. Traumatic neuropathies: spectrum of imaging findings and postoperative assessment. Semin Musculoskelet Radiol 2010;14:512-22.

50 Zhu J, Liu F, Li D, et al. Preliminary study of the types of traumatic peripheral nerve injuries by ultrasound. Eur Radiol 2011;21:1097-101.

51 Katona I, Weis J. Diseases of the peripheral nerves. Handb Clin Neurol 2017; 145:453-74.

52 Lemont $\mathrm{H}$, Ammirati KM, Usen N. Plantar fasciitis: a degenerative process (fasciosis) without inflammation. J Am Podiatr Med Assoc 2003;93:234-7.

53 McNally EG, Shetty S. Plantar fascia: imaging diagnosis and guided treatment. Semin Musculoskelet Radiol 2010;14:334-43

54 Zhang J, Nie D, Rocha JL, et al. Characterization of the structure, cells, and cellular mechanobiological response of human plantar fascia. J Tissue Eng 2018;9:2041731418801103

55 Smith J, Finnoff JT. Diagnostic and interventional musculoskeletal ultrasound: Part 1. fundamentals. Pm R 2009;1:64-75.

56 Elzinga KE, Morhart MJ. Needle Aponeurotomy for Dupuytren disease. Hand Clin 2018:34:331-44.

57 Morhart M. Pearls and pitfalls of needle aponeurotomy in Dupuytren's disease. Plast Reconstr Surg 2015;135:817-25.

58 Gatt DL, Charalambous CP. Ultrasound-Guided barbotage for calcific tendonitis of the shoulder: a systematic review including 908 patients. Arthroscopy 2014;30:1166-72.

59 Johnston E, Scranton P, Pfeffer GB. Chronic disorders of the Achilles tendon: results of conservative and surgical treatments. Foot Ankle Int 1997;18:570-4.

60 Simon WH. Soft tissue disorders of the shoulder. frozen shoulder, calcific tendintis, and bicipital tendinitis. Orthop Clin North Am 1975;6:521-39.
61 Mitra R, Harris A, Umphrey C, et al. Adhesive capsulitis: a new management protocol to improve passive range of motion. Pm $R$ 2009;1:1064-8.

62 Stover D, Fick B, Chimenti RL, et al. Ultrasound-Guided tenotomy improves physical function and decreases pain for tendinopathies of the elbow: a retrospective review. $J$ Shoulder Elbow Surg 2019;28:2386-93.

63 Solheim E, Hegna J, Øyen J, et al. Arthroscopic treatment of lateral epicondylitis: tenotomy versus debridement. Arthroscopy 2016;32:578-85.

64 Nazarian LN, Gulvartian NV, Freeland EC, et al. Ultrasound-Guided percutaneous needle fenestration and corticosteroid injection for anterior and anterolateral ankle impingement. Foot Ankle Spec 2018;11:61-6.

65 Finnoff JT, Johnson W. Ultrasound-Guided fasciotomy for chronic exertional compartment syndrome: a case report. Clin J Sport Med 2020;30:e231-3.

66 Lueders DR, Sellon JL, Smith J, et al. Ultrasound-Guided fasciotomy for chronic exertional compartment syndrome: a cadaveric investigation. $P m$ R 2017;9:683-90.

67 Bazzocchi A, Pelotti P, Serraino S, et al. Ultrasound imaging-guided percutaneous treatment of rotator cuff calcific tendinitis: success in short-term outcome. Br J Radiol 2016;89:20150407.

68 Courseault J, Kessler E, Moran A, et al. Fascial Hydrodissection for chronic hamstring injury. Curr Sports Med Rep 2019;18:416-20.

69 Fried SM, Nazarian LN. Ultrasound-Guided Hydroneurolysis of the median nerve for recurrent carpal tunnel syndrome. Hand 2019;14:413-21.

70 Wu Y-T, Chen S-R, Li T-Y, et al. Nerve hydrodissection for carpal tunnel syndrome: a prospective, randomized, double-blind, controlled trial. Muscle Nerve 2019;59:174-80

71 Norman G, Atkinson RA, Smith TA, et al. Intracavity lavage and wound irrigation for prevention of surgical site infection. Cochrane Database Syst Rev 2017:10:CD012234.

72 Dass RM, Kim E, Kim H-K, et al. Alcohol neurolysis of genicular nerve for chronic knee pain. Korean J Pain 2019:32:223-7.

73 Karri J, Zhang B, Li S. Phenol neurolysis for management of focal spasticity in the distal upper extremity. Pm $R$ 2020;12:246-50.

74 Sautier E, Neri T, Gresta G, et al. Endoscopic neurolysis of the ulnar nerve: retrospective evaluation of the first 60 cases. J Shoulder Elbow Surg 2017:26:1037-43.

75 Debrule MB. Ultrasound-Guided Weil percutaneous plantar fasciotomy. J Am Podiatr Med Assoc 2010;100:146-8.

76 Pourcho AM, Hall MM. Percutaneous ultrasonic fasciotomy for refractory plantar Fasciopathy after failure of a partial endoscopic release procedure. $P M \& R$ 2015;7:1194-7.

77 Alfredson H. Ultrasound and Doppler-guided mini-surgery to treat midportion Achilles tendinosis: results of a large material and a randomised study comparing two scraping techniques. Br J Sports Med 2011;45:407-10.

78 Hall MM, Rajasekaran S. Ultrasound-Guided Scraping for chronic patellar tendinopathy: a case presentation. PM\&R 2016;8:593-6.

79 Riggin CN, Chen M, Gordon JA, et al. Ultrasound-Guided dry Needling of the healthy rat supraspinatus tendon elicits early healing without causing permanent damage. $J$ Orthop Res 2019:37:2035-42.

80 Testa V, Capasso G, Benazzo F, et al. Management of Achilles tendinopathy by ultrasound-quided percutaneous tenotomy. Med Sci Sports Exerc 2002:34:573-80.

81 Sconfienza LM, Mauri G, Messina C, et al. Ultrasound-Guided percutaneous tenotomy of biceps tendon: technical feasibility on cadavers. Ultrasound Med Biol 2016;42:2513-7.

82 McShane JM, Nazarian LN, Harwood MI. Sonographically guided percutaneous needle tenotomy for treatment of common extensor tendinosis in the elbow. J Ultrasound Med 2006;25:1281-9.

83 Wu Y-Y, He F-D, Chen K, et al. Comparison of the clinical effectiveness of ultrasoundguided corticosteroid injection with and without needle release of the A1 pulley in treating trigger finger. J Xray Sci Technol 2020;28:573-81.

84 Pan M, Sheng S, Fan Z, et al. Ultrasound-Guided percutaneous release of A1 Pulley by using a needle knife: a prospective study of 41 cases. Front Pharmacol 2019;10:267.

85 Krey D, Borchers J, McCamey K. Tendon needling for treatment of tendinopathy: a systematic review. Phys Sportsmed 2015;43:80-6. 